\title{
Wolf Parkinson White sendromu (WPW) ablasyonu yapılan hastaların özellikleri: Tek merkez vaka serisi
}

\section{Characteristics of patients with Wolf Parkinson's White syndrome (WPW) ablation: Single center case series}

\author{
Selçuk KANAT* Ahmet TÜTÜNCÜ घ
}

Sağlık Bilimleri Üniversitesi, Bursa Yüksek İhtisas Eğitim ve Araştırma Hastanesi, Kardiyoloji Kliniği, Bursa/TÜRKIYE

\section{öz}

Amaç: Aksesuar yol varlığı ile oluşan atriyoventriküler reentran taşikardiler (AVRT) paroksismal supraventriküler taşikardilerin yaklaşık dörtte birini oluşturur. Bizim retrospektif çalışmamızın amacı katater ablasyon işlemi yapılan yüksek volümlü bir merkezde, AVRT ablasyon yapılan hastaların demografik özellikleri, etiyolojik faktörler ve komplikasyon oranları hakkında bilgi vermektir.

Gereç ve Yöntemler: Hastanemizin kardiyoloji kliniğinde Ocak 2014 ve Ocak 2018 yılları arasında SVT ablasyonu uygulanan 1107 hasta tarandı ve katater ablasyon yapılmış 232 WPW 'li hasta çalışmaya dahil edildi. Bu hastalar demografik özellikleri, etiyolojik faktörleri, aksesuar yol lokalizasyonları, işlem başarısı ve komplikasyon gelişimi açısından değerlendirilmiştir.

Bulgular: Hastaların yaş ortalaması $38 \pm 16,1$ olup ve kadın cinsiyet oranı \%37.1 dir. En sık görülen lokalizasyonun sol aksesuar kaynaklı yolak olduğu görüldü $(\% 53,1)$. Tüm lokalizasyonlar için akut dönemde işlem başarısı \%93,1 saptandı. Tüm hastalarda karşılaşılan komplikasyon oranı \% 3,3 iken, en sık karşılaşılan komplikasyon girişim yeri hematomu olarak karşımıza çıkmıştır(\% 2,1).

Tartışma: Tüm yaş gruplarını etkileyebilen ve yaşam kalitesini oldukça kötüleştirebilen bir hastalık grubu supraventriküler taşikardiler (SVT) dir. Bu grubun ikinci sıklıkta görülen üyesi AVRT'nin bilinen küratif tedavisi radyofrekans katater (RF) ablasyondur. Ablasyon tedavisi yapan hekim sayısı ve işlemin yapıldığı merkez sayısı giderek artış göstermektedir. Özellikle gelişebilecek komplikasyonlar açısından dikkat çekmek amaçlı AVRT ablasyon tecrübelerimiz bu çalışma ile sunulmuştur.

Anahtar kelimeler: atriyoventriküler; aksesuar yol, komplikasyon

Sorumlu Yazar*: Selçuk Kanat, Sağlık Bilimleri Üniversitesi, Bursa Yüksek İhtisas Eğitim ve Araştırma Hastanesi, Kardiyoloji Kliniği, Bursa/TÜRKiYE Eposta: drselcukkanat@gmail.com

ORCID:

Received : 01.02.2019 Accepted: 26.02.2019

Doi: $10.18663 /$ tjcl.520712 


\section{ABSTRACT}

Aim: Atrioventricular reentrant tachycardia (AVRT) formed by the presence of accessory pathway accounts for about one quarter of paroxysmal supraventricular tachycardias. In our retrospective study, demographic characteristics, etiological factors and complication rates of patients undergoing AVRT ablation were reported in a high-volume center where catheter ablation was performed.

Material and Methods: In our cardiology clinic, between January 2014 and January 2018, 1107 patients who underwent SVT ablation were screened and 232 WPW patients with catheter ablation were included in the study. These patients were evaluated in terms of their demographic characteristics, etiological factors, accessory path localizations, operation success and complication development.

Results: The mean age of the patients was $38 \pm 16.1$ and the female gender percentage was 37.1. The most common localization was found to be left accessory origin (53.1\%). While the complication rate was $3.3 \%$ in all patients, the most common complication was seen as a site of hematoma (2.1\%).

Discussion: Supraventricular tachycardia (SVT) is a group of diseases that can affect all age groups and can impair the quality of life. The second most common of this group is AVRT. Catheter ablation, is the known curative treatment of it. The number of physicians performing ablation treatment and the number of centers in which the procedure is performed increase. Our experience with AVRT ablation was reported with this study.

Keywords: atrioventricular; accessory pathway, complication

\section{Giriş}

Atriyoventriküler reentran taşikardi (AVRT); anatomik olarak normal ileti sistemi ve aksesuar ileti yolun farklı ileti süresi ve refrakter özellik göstermesi nedeniyle prematür ekstrasistol veya ventriküler ekstra sistol ile oluşabilen makroreentran taşikardilerdendir [1]. Paroksismal supraventriküler taşikardilerin yaklaşık dörtte birini oluşturur. Artan yaşla birlikte azalma eğiliminde olup erkeklerde biraz daha fazla görülme eğimindedir [2]. Aksesuar yollar atriyoventriküler nodal ileti yolundan farklı özellikler gösterirler. Aksesuar yolun her iki anterograd ve retrograd iletisi sık olmakla birlikte sadece retrograd iletisi olan ve en nadir sadece anterograd iletisi olmak üzere farklılıklar gösterir[3]. Yüzeyel asemptomatik EKG de belirgin delta dalgaları olup supraventriküler taşikardi ataklarılya seyretmesine Wolf-Parkinson-White sendromu (WPW) denir.

Akseuar ileti özelliğine göre AVRT taşikardiler ortodromik ve antidromik olmak üzere ikiye ayrılırlar. AVRT'lerin \%95'i ortodromik özellik gösterirler [1]. AVRT'lerin kronik dönem tedavisinde ablasyon işlemi önerilmektedir[4, 5]. Ablasyon işleminde komplikasyon oranıyaklaşık\%2,8 civarındadır[6]. Ancak deneyimli merkezlerde bu oranlar daha da düşük görülmektedir.
Bu çalışmanın amacı yaklaşık 5 yıllık dönemde RF ablasyon yaptığımız AVRT hastalarının karakteristik özelliklerini, başarı ve komplikasyon oranlarını bildirmektir.

\section{Gereç ve Yöntemler}

Çalışmamızda; Ocak 2014 ve Ocak 2018 yılları içinde kardiyoloji kliniğimizde SVT ablasyonu uygulanan 1107 hasta tarandı ve RFA yapılmış 232 WPW 'li hasta dahil edildi. (Resim 1) Tüm hastalardan çalışmaya dahil edilebilmeleri imzalı onay formları alındı, çalışma için hastanemiz etik kurulundan onay alındı. Framingham koroner arter risk sınıflamasına göre orta ve yüksek saptanan hastalara ek olarak femoral arter yolu ile koroner anjiyografi yapıldı. Hastaların diyabetik, hipertansif, hiperlipidemik olup olmadığı kaydedildi. Antekübital venden alınmış rutin kan örneğinden çalışılan sonuçlar kayıt edildi. Rutin ekokardiyografik değerlendirmede (Vivid-7, GE Wingmed sound Horten, Norway); sol atriyum çapı (LAD), sol ventrikül sistolik ve diastolik çapları, sol ventrikül duvar kalınlıkları ve ejeksiyon fraksiyonu hesaplandı. Aksesuar yol lokasyonlarına göre işlem başarısı ile ilgili klinik sonuçlar ve girişimsel değişkenler kayıt altına alındı. Çalışma için yerel etik kurul onayı alındı. Hasta onam formları imzalatıldı. 


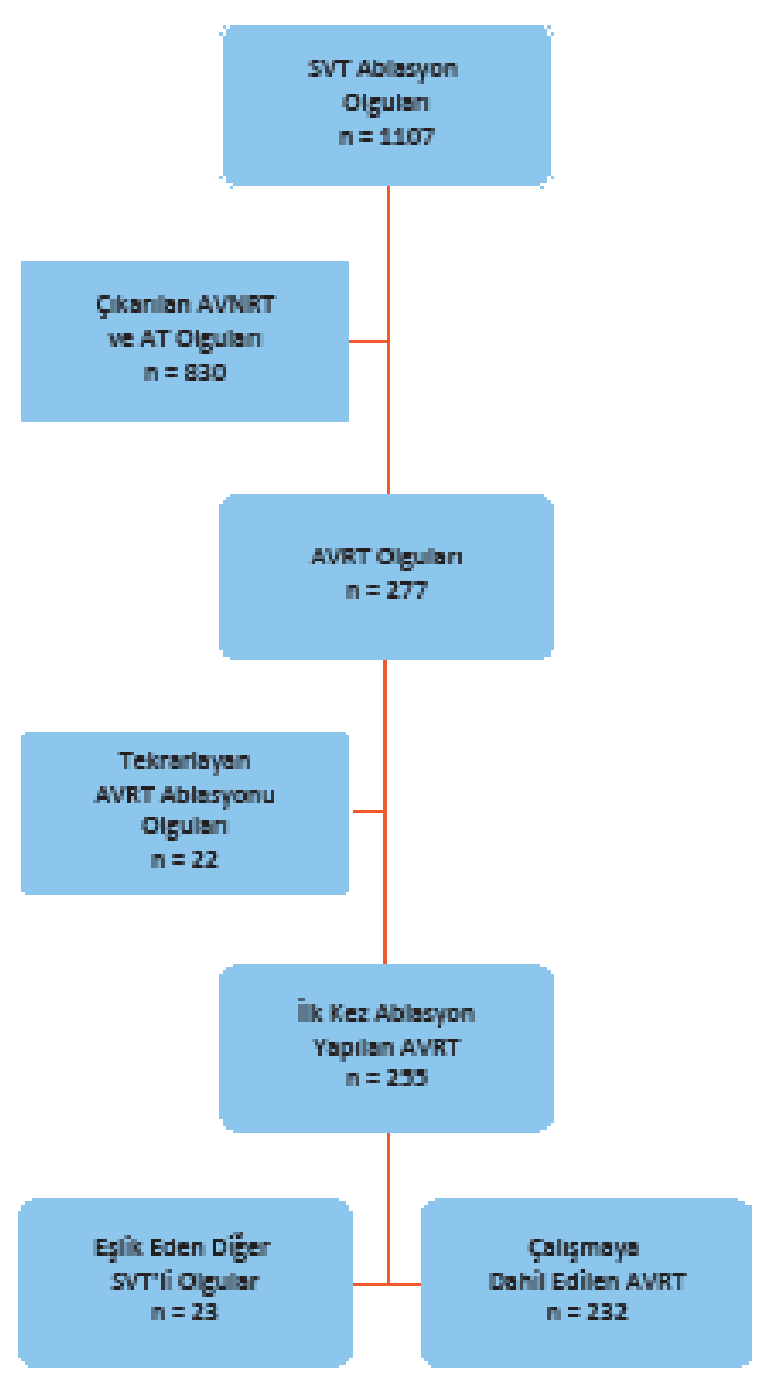

Figür 1 AVRT Ablasyon çalışması akış şeması.

\section{Elektrofizyolojik çalışma}

Bütün hastaların katater ablasyon tedavisi öncesi bilgilendirilmiş onamları alındı. Hastaların kullandıkları antiaritmik ilaç tedavisi en az beş yarı ömür öncesinden kesildi. Tüm prosedürler lokal anestezi altında yapıldı. Elektrofizyolojik çalışma ve ablasyon tedavisi femoral bölgeden kateterler yerleştirilerek EP Tracer cihazı (Medtronic, Inc., USA) ile yapıldı. Dört kutuplu tanısal kateter $\left(6 \mathrm{~F}, 110 \mathrm{~cm}\right.$, Marinr ${ }^{\circledast} \mathrm{SC}$ Series, Medtro nic, Minneapolis, MN, USA) yüksek lateral sağ atriyuma yerleştirildi. Ek olarak on kutuplu tanısal katater (6F , $110 \mathrm{~cm}$, Inquiry ${ }^{\mathrm{TM}}$,St. Jude Medical , St. Paul, Minnesota, USA) koroner sinüse femoral ven yada sağ internal juguler ven yolu ile yerleştirildi. Ayrıca dört kutuplu RFA kateteri $(7 F, 110 \mathrm{~cm}$, RF Mariner ${ }^{\circledR} M C$, Medtronic, USA) his kaydının alındığı sağ ventrikül bölgesine yerleştirildi. İlk olarak; Atriyum-His (A-H) ve His -Ventrikül $(\mathrm{H}-\mathrm{V})$ süreleri, Wenckebach noktası, atriyum, ventrikül, AV nod ve aksesuar yol efektif refrakter periyotları ölçüldü ve kayıt altına alındı. Aksesuar yolun lokalizasyonu, koroner sinüs kateterinin rehberliği ya da ablasyon katateri ile tespit edildi. Preeksitasyonu belirgin olmayan hastalarda atriyal pacing ile preeksitasyon görünür hale getirildi. Gizli aksesuar yolu olan hastalarda AVRT'yi indüklemek için programlı veya burst atriyal ya da ventriküler pacing protokolleri uygulandı. Taşikardinin indüklenmediği durumlarda isoproterenol (2-6 $\mathrm{mcg} / \mathrm{kg} / \mathrm{min}$ ) ya da atropin (0.6-1.0 mg) ile sinüs ritmi en az yüzde 20 arttırıldıktan sonra uyarılar tekrarlanarak AVRT indüklendi. Taşikardi indüklendikten sonra AVRT tanısı yaygın olarak kabul edilen kriterlere göre yapıldı [7] (Resim 2 ).

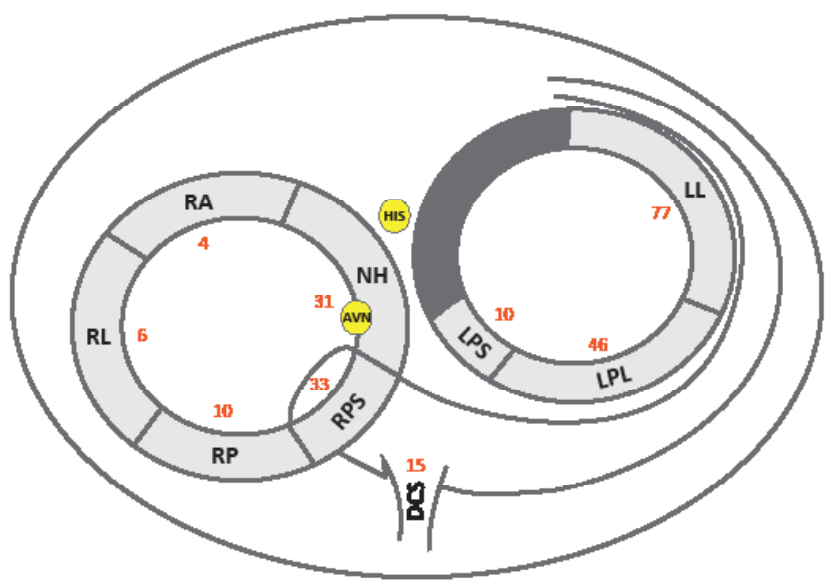

Figür 2 Aksesuar yol ablasyon lokalizasyon dağılımı.

\section{Radyofrekans ablasyon}

Temel elektrofizyolojik çalışmanın tamamlanmasından sonra, WPW ablasyonu RFA kateteri $\left(7 F, 110 \mathrm{~cm}\right.$, RF Mariner ${ }^{\circledR}$ MC, Medtronic, USA) ile floroskopik anatomik belirteçler ve karakteristik intrakardiyak elektrokardiyogram kılavuzluğunda gerçekleştirildi. Atriyoventriküler (AV) bileşkede bulunan aksesuar yollar, manifest aksesuar yollarda sinüs ritmi sırasındaki AV füzyon ile gizli WPW sendromlarda ise ventrikül pacing yada ortadromik AVRT sırasında VA füzyonu gösteren elektrogramlar kullanılarak tespit edildi.

Sol taraflı aksesuar yolların ablasyonu transaortik retrograd ya da transseptal ponksiyon yolu ile gerşekleştirildi. (Resim 2) RFA Isı kontrol modda $\left(50^{\circ}-60^{\circ} \mathrm{C}\right.$ and $\left.30-50 \mathrm{~W}\right)$ uygulandı. Midseptal ve anteroseptal yerleşimli nodo-hisian aksesuar yollar ise RF enerji ile $40^{\circ} \mathrm{C}$ ile başlanıp AV blok ya da nodal ritim gelişmediği taktirde enerji basamaklı olarak arttırılıp işlem tamamlandı. Eğer AV blok riski oluşuyor ise RFA 'dan daha güvenli olan kryoenerji kullanıldı[8]. Derin koroner sinüs kaynaklı aksesuar yol ablasyonunda ise irrigasyonlu RF ablasyon katateri (FlexAbility ${ }^{\circledR}$, DF curve, St. Jude Medical) kullanıldı. (Resim 3) RFA güç kontrol modda (25-35 W) gerçekleştirildi. Özellikle sağ taraflı WPW ablasyonunda RFA kateter stabilitesinin yetersiz olması durumunda uzun bir kılıf ( Agilis ${ }^{\circledR}$ NxT Steerable Introducer, St. Jude Medical, St. Paul, MN, ABD) kullanıldı. RF prosedürün 
bitiş noktası, yüzeyel EKG'de delta dalgasının kaybolması, aksesuar iletinin antegrad ve retrograd kaybolması ve taşikardi indüklenmemesi olarak kabul edildi. Tüm hastalardan işlem sonrası elektrokardiyogramlar alınıp ekokardiyografi ile perikardiyal efüzyon varlığı değerlendirildi. Taburculuk sonrası 1. ayda poliklinik kontrolüne çağrılıp 6 aylık aralıklarla telefonla aranıp nüks ve komplikasyon açısından takip edildi.

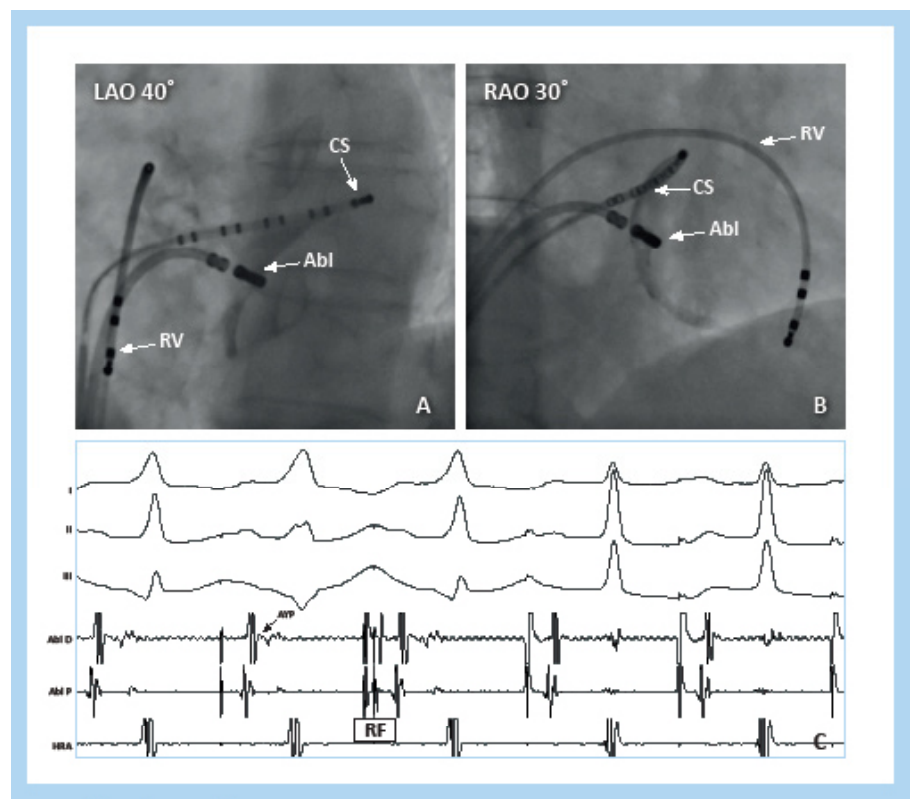

Figür 3 Derin koroner sinüs ven kaynaklı aksesuar yol ablasyonu.

\section{İstatistiksel Analiz}

İstatiksel çalışma SPSS 17 (SPSS Inc., Chicago, IL, United States) paket bilgisayar programı kullanılarak yapıldı. Normal dağııım gösteren değişkenler ortalama \pm standart sapma, normal dağılım göstermeyen değişkenler ise medyan (interquartile range: IQR) olarak ifade edildi. Kategorik değişkenler ise sıklık ve yüzde (\%) olarak verildi. Normal dağılan sayısal değişkenlerin iki farklı grupta karşılaştırımasında Student's t testi kullanılırken, normal dağılmayan sayısal değişkenler için Mann Whitney $U$ testi kullanıldı. Nominal verilerin karşılaştırılması için ki-kare ya da Fisher's exact testleri kullanıldı. Çalışmamızda üç grup arasındaki farkın belirlenmesine yönelik Bonferroni çoklu karşılaştırma testi kullanıldı. p değeri $<0.05$ anlamlı olarak kabul edildi.

\section{Bulgular}

Çalışmada yaş ortalaması $38 \pm 16,1$ yıl olarak saptanmıştır. Kadın cinsiyet oranı ise \% 37,1 olarak görüldü. Aksesuar yolların $\% 59,9$ 'nun manifest aksesuar yolak olduğu tespit edildi. Manifest aksesuar yola sahip hastaların asemptomatik olma oranı \%32,4 olup, çalışmaya dahil edilen tüm aksesuar yol ablasyonu uygulanan hastalarda bu oran \%19,4 saptanmıştır. Çalışma grubunun demografik özellikleri, laboratuar bulguları ve ekokardiyografik ölçümleri Tablo 1'de sunulmuştur. Çalışmaya alınan hastalara koroner anjiyografi yapılma oranı $\% 18,9$ olarak saptandı. Uyarılan AVRT'lerin \%8.6'sı sağ aksesuar, \%38,3'ü septal aksesuar ve \%53,1'i sol aksesuar kaynaklı olduğu görüldü. (Resim 4) Hastaların \% 9,1 inde en sık atriyoventriküler nodal reentran taşikardi olmak üzere ikinci bir atriyal aritmi tespit edildi. İslem süresi $79 \pm 16$ dakika, floroskopi süresi $28 \pm 7,7$ dakika ve toplam ablasyon süresi $368 \pm 47$ saniye olarak ölçülmüştür.

\begin{tabular}{|c|c|}
\hline & Tüm Hastalar n=232 \\
\hline Yaş & $38 \pm 16.1$ \\
\hline Kadın Cinsiyet, n (\%) & $86(37.1)$ \\
\hline Sigara, n (\%) & $30(12.9)$ \\
\hline Hipertansiyon, n (\%) & $17(0.3)$ \\
\hline Hiperlipidemi, n (\%) & $14(6)$ \\
\hline Diyabetes Mellitus, n (\%) & $10(4.3)$ \\
\hline LVEF (\%) & $57.9 \pm 5.1$ \\
\hline Septal kalınlık,mm & $0.78 \pm 0.18$ \\
\hline Posterior duvar kalınlık, mm & $0.81 \pm 0.2$ \\
\hline Sol ventrikül diastolic çap , mm & $45 \pm 3.7$ \\
\hline Sol ventrikül sistolic çap , mm & $29 \pm 3.7$ \\
\hline Sol atrial çap, mm & $30 \pm 2.8$ \\
\hline $\mathrm{LDL}, \mathrm{mg} / \mathrm{dL}$ & $109 \pm 46$ \\
\hline $\mathrm{HDL}, \mathrm{mg} / \mathrm{dL}$ & $41 \pm 11$ \\
\hline Trigliserid, mg/dL & $161 \pm 60$ \\
\hline Glukoz, mg/dL & $92 \pm 16$ \\
\hline Kreatinine, mg/dL & $0.8 \pm 0.88$ \\
\hline Sodyum, mg/dl & $139 \pm 2.9$ \\
\hline Potasyum,mg/dl & $4.2 \pm 1.1$ \\
\hline Hemoglobin, $\mathrm{g} / \mathrm{dL}$ & $13.1 \pm 1.2$ \\
\hline WBC, $x 109 / L$ & $7.1 \pm 1.8$ \\
\hline Tiroid Stimulan Hormon, mU/L & $1.35 \pm 1.0$ \\
\hline $\begin{array}{l}\text { LVEF: Sol ventriküler ejeksiyon fraksiy } \\
\text { poprotein; HDL:Yüksek yoğunluklu lip }\end{array}$ & $\begin{array}{l}\text { LDL: Düšük yoğunluklu } \\
\text { sin;WBC: beyazkan hücre }\end{array}$ \\
\hline
\end{tabular}

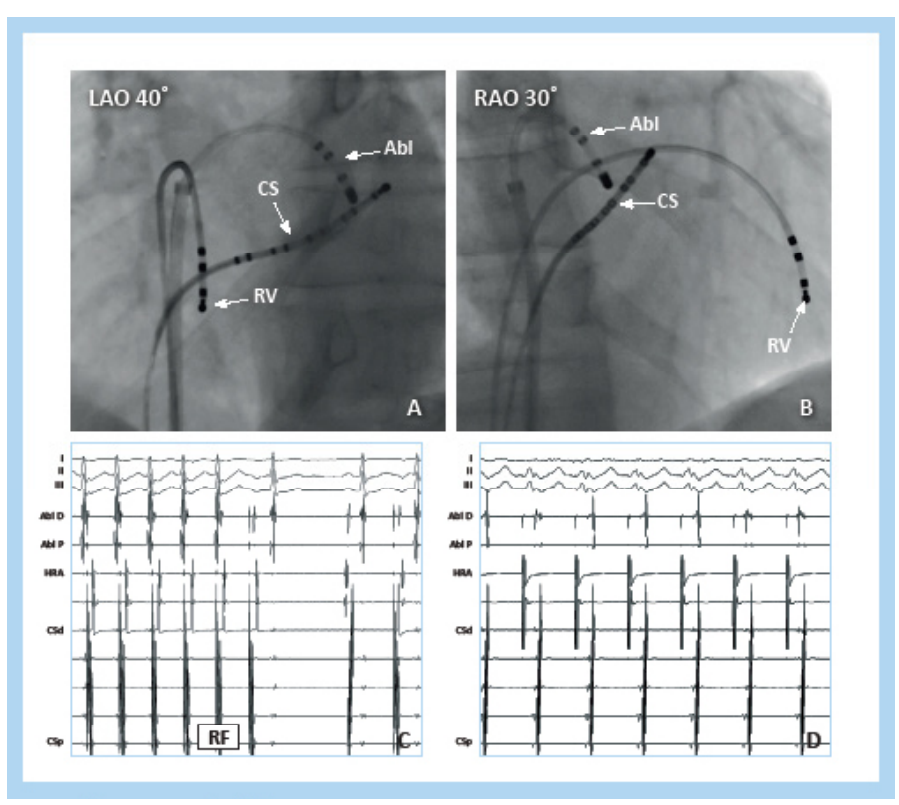


Figür 4 Sol lateral yerleşimli gizli aksesuar yol ablasyonu.

Akut dönemde işlem başarısı \%93,1 iken uzun dönem işlem başarısı literatüre benzer şekilde \%89,2 olarak karşımıza çıkmıştır. Tüm hastalarda karşılaşılan komplikasyon oranı \% 3,3 iken, en sık karşılaşılan komplikasyon girişim yeri hematomu olarak saptandı $(\% 2,1)$. AV tam blok ise literatüre benzer şekilde \%0.8 olarak saptanmıştır. Hasta gruplarının prosedür özellikleri ve komplikasyon sıklıkları Tablo 2'de sunulmuştur.

\begin{tabular}{|c|c|}
\hline & $\begin{array}{c}\text { Tüm Hastalar } \\
n=232\end{array}$ \\
\hline $\begin{array}{l}\text { Aksesuar yolak dağılımı, n (\%) } \\
\text { Sağ anterior } \\
\text { Sağ lateral } \\
\text { Sağ posterior } \\
\text { Sağ paraseptal } \\
\text { Nodo-hisian } \\
\text { Derin koroner sinus } \\
\text { Sol paraseptal } \\
\text { Sol posterolateral } \\
\text { Sol lateral }\end{array}$ & $\begin{array}{l}4(1.7) \\
6(2.6) \\
10(4.3) \\
33(14.2) \\
31(13.3) \\
15(6.4) \\
10(4.3) \\
46(19.8) \\
77((33.2)\end{array}$ \\
\hline $\begin{array}{l}\text { Eşlik eden diğer ritim bozuklukları, } \mathrm{n}=255 \text { (\%) } \\
\text { AVNRT } \\
\text { Fokal atriyal taşikardi } \\
\text { Atriyal fibrilasyon/flutter }\end{array}$ & $\begin{array}{c}10(3.9) \\
5(1.9) \\
8(3.1)\end{array}$ \\
\hline Koroner anjio girişimi, n (\%) & $44(18.9)$ \\
\hline Akut işlem başarısı, n (\%) & $213(93.1)$ \\
\hline Uzun dönem işlem başarısı, n (\%) & $207(89.2)$ \\
\hline İşlem Süresi, dakika & $79 \pm 16$ \\
\hline Ablasyon Süresi, saniye & $368 \pm 47$ \\
\hline Floroskopi Süresi, dakika & $28 \pm 7.7$ \\
\hline Ölüm, n (\%) & $0(0)$ \\
\hline Girişim yeri hematomu, n (\%) & $5(2.1)$ \\
\hline AV Tam blok, n (\%) & $2(0.8)$ \\
\hline Tamponad, n (\%) & $1(0.04)$ \\
\hline AVNRT, Atriyoventriküler nodal reentran taşikardi ; & \\
\hline
\end{tabular}

Aksesuar yol lokasyonlarına göre işlem başarısı ile ilgili klinik sonuçlar ve girişimsel değişkenler karşılaştırıldığında; sağ, septal ve sol kaynaklı aksesuar yol ablasyonunda akut işlem başarısı ve rekürrens oranlarında fark saptanmadı. ( sırasıyla; 18 (90\%) \& 81(91\%) \& $114(\% 92,6) p=0,71 / 1(5 \%) \& 2(2,2 \%) \& 3$ $(2,4 \%) \quad p=0,24)$ Floroskopi süresi ve işlem süresi sol kaynaklı aksesuar yol ablasyonunda daha düşük saptanmıştır. ( sırasıyla; $31,8 \pm 10,7 \& 27,7 \pm 11,7 \& 20,6 \pm 7,9 p<0,05 / 79 \pm 16,4 \& 72 \pm$ $15,9 \& 56 \pm 12,7 p<0,05$ ) Total ablasyon süresi ise sağ kaynaklı aksesuar yol ablasyonunda daha yüksek saptanmıştır. ( sırasıyla; $407 \pm 63 \& 271 \pm 38 \& 305 \pm 41 p<0,05$ ) İşlem başarısı ile ilgili klinik sonuçlar ve girişimsel değişkenler Tablo 3'de sunulmuştur.

\begin{tabular}{|c|c|c|c|c|}
\hline Değişkenler & $\begin{array}{l}\text { Sağ } \\
\text { aksesuar } \\
(n=20)\end{array}$ & $\begin{array}{l}\text { Septal } \\
\text { aksesuar } \\
(n=89)\end{array}$ & $\begin{array}{l}\text { Sol } \\
\text { aksesuar } \\
(n=123)\end{array}$ & $\begin{array}{c}P \\
\text { değeri }\end{array}$ \\
\hline Yaş (yıl) & $\begin{array}{c}37,8 \pm \\
15,8\end{array}$ & $\begin{array}{c}39,2 \pm \\
17,1\end{array}$ & $\begin{array}{c}38,2 \pm \\
16,3\end{array}$ & 0,79 \\
\hline Cinsiyet (kadın) & $35,9 \%$ & $39,9 \%$ & $37,2 \%$ & 0,88 \\
\hline Hipertansiyon & $7,4 \%$ & $7,1 \%$ & $7,3 \%$ & 0,80 \\
\hline Diyabetes Mellitus & $4 \%$ & $4,2 \%$ & $4,4 \%$ & 0,91 \\
\hline Akut işlem başarısı & $18(90 \%)$ & $81(91 \%)$ & $\begin{array}{c}114 \\
(\% 92,6)\end{array}$ & 0,71 \\
\hline Rekürrens & $1(5 \%)$ & $2(2,2 \%)$ & $3(2,4 \%)$ & 0,24 \\
\hline İşlem Süresi (dakika) & $\begin{array}{c}79 \pm 16,4 \\
a\end{array}$ & $\begin{array}{c}72 \pm \\
15,9 a\end{array}$ & $\begin{array}{c}56 \pm \\
12,7 b\end{array}$ & $<0,05$ \\
\hline $\begin{array}{l}\text { Florosokopi Süresi } \\
\text { (dakika) }\end{array}$ & $\begin{array}{l}31,8 \pm \\
10,7 \mathrm{a}\end{array}$ & $\begin{array}{l}27,7 \pm \\
11,7 \mathrm{a}\end{array}$ & $\begin{array}{c}20,6 \pm 7,9 \\
b\end{array}$ & $<0,05$ \\
\hline $\begin{array}{l}\text { Total ablasyon } \\
\text { Süresi (saniye) }\end{array}$ & $\begin{array}{c}407 \pm \\
63 b\end{array}$ & $\begin{array}{c}271 \pm \\
38 a\end{array}$ & $\begin{array}{c}305 \pm 41 \\
a\end{array}$ & $<0,05$ \\
\hline $\begin{array}{l}\text { Total komplikasyon } \\
\text { oranı }\end{array}$ & $5 \%$ & $2,7 \%$ & 2,9 & 0,58 \\
\hline \multicolumn{5}{|c|}{$\begin{array}{l}\mathrm{P}<0,05 \text { istatistiksel olarak anlamlı kabul edildi . a,b,c aynı harfler, } \\
\text { Bonferroni çoklu karşılaştırma testlerine dayanan gruplar arasında } \\
\text { anlamlı bir fark olmadığını gösteriyor. }\end{array}$} \\
\hline
\end{tabular}

\section{Tartışma}

Aksesuar yol ablasyonu uygulanan hastalarımızın akut ve uzun dönem başarısı sırasıyla \%93,1 - \%89,2 saptanmış olup, başarılı ablasyon lokalizasyonlarına göre sınıflandırıldıklarında \%8.6 'sı sağ serbest duvar kaynaklı, \%38,3'ü septal /derin koroner sinüs ve $\% 53,1$ 'i sol aksesuar kaynaklı olduğu saptandı. Bu oran Arruda MS ve ark. yaptığı çalışmayla kıyaslandığında, benzer yaş, cinsiyet ve lokalizasyon dağılım oranlarına sahip olduğu görülmektedir[9]. Başarı oranlarına bakıldığında, Calkins H ark. yaptığı vaka serisinde akut ablasyon başarısı \%93, nüks oranı ise $\% 8$ saptanmış olup, çalışmamızda nüks oranı \%3,9 ile daha düşük tespit edilmiştir[10]. Vaka serimizde, komplikasyon oranlarına bakıldığında, tüm komplikasyon oranı \% 2,9 olup, kalıcı kalp pili gerektiren AV blok $(\% 0,4)$, kan transfüzyonu yada cerrahi işlem gerektiren girişim yeri hematomu $(\% 0,8)$, tamponad $(\% 0,4)$ gibi majör komplikasyonların oranı \% 1,6 olarak saptanmıştır ancak ölüm izlenmemiştir. Bu sonuçlar Spector P. ve ark. atriyal flutter ve supraventriküler taşikardi ablasyonu yapılan hastalardan oluşan vaka serisiyle kıyaslandığında benzer oranlarda olduğu görülmektedir [11]. Çalışmaya alınan hastalarda, işlem süresi $79 \pm 16$ dakika, 
floroskopi süresi $28 \pm 7,7$ dakika ve toplam ablasyon süresi $368 \pm 47$ saniye ölçülmüştür. Önceki çalışmalar, eğitimli operatörler tarafından uygulanan CARTO (Biosense, Diamond Bar, CA, ABD) ve EnSite NavX (St. Jude Medical, Saint Paul, MN, ABD) gibi yaygın kullanılan bilgisayar tabanlı iç boyutlu elektroanatomik haritalama sistemleri(3D-EAM) ile konvansiyonel RFCA yöntemleri karşılaştırıldığında radyasyona maruzuyeti azaltabileceğini göstermiştir[12,13]. Jorge R. ve ark. yaptıkları çalışmanın subgrup analizinde, çalışmaya alınan ve yaklaşık dörtte biri WPW 'li olan 522 SVT ablasyonu yapılan olgular değerlendirilmiş. 3D-EAM ve konvansiyonel RFCA yapılan olgular karşılaştırıldığında, her iki grup arasında benzer akut başarı ve komplikasyon oranları tespit edilmiştir. İşlem, floroskopi ve ablasyon süreleri karşılaştırıldığında konvansiyonel RFCA yapılan grupta daha kısa saptandığı görülmüştür. 3D- EAM sistemlerinin özellikle tecrübenin az olduğu merkezlerde kullanılması, floroskopi süresini önemli ölçüde azaltmadığı ve geleneksel haritalama ile karşılaştırıldığında akut sonuçları iyileştirmediği vurgulanmıştır. Çalışmamıza dahil edilen hastaların tamamı konvansiyonel haritalama kullanılarakyapılmış olup, Jorge R. ve ark. yapmış olduğu bu çalışma ile kıyaslandığında, işlem süresi daha kısa olduğu ve floroskopi süresi ise 3D- EAM ile yapılan ablasyon grupları ile eşit olduğu görülmektedir. (Sırasıyla 272.9 \& 79 dakika / 28 \& 27.3 dakika)[14]. Bu bulgular; kateter manipülasyonu sırasında floroskopi kullanımını azaltarak güvenliği artırmasına izin veren; intrakardiyak ultrason, destek kataterlerinin 3D-EAM kullanımındaki tecrübelerin geliştirilmesinin gerekli olduğu fikrini desteklemektedir.

Vaka serimizde, aksesuar yolların \%59,9'nun manifest aksesuar yolak olduğu tespit edildi ve manifest aksesuar yola sahip hastaların asemptomatik olma oranı \%32,4 olduğu saptandı. Preeksitasyonu olup senkop veya çarpıntı gibi semptomlar eşlik eden semptomatik WPW sendromlu hastalarda, yaşam boyu \% 4'e yakın ani kalp ölümü (AKÖ) riski vardır. Bu nedenle, bu semptomatik hastaların, özellikle elektrofizyolojik (EP) bir çalışma ile risk sınıflandırması ve aksesuar yolunun kateter ablasyonu önerilmektedir[15]. Bununla birlikte, elektrokardiyografik preeksitasyon saptanan hastalar, asemptomatik olduklarında, aritmik olayların sıklığı ve AKÖ riski açık değildir. Bununla birlikte elektrokardiyografide preeksitasyon saptanan hastaların ilk semptomu AKÖ olabilir[16].Pappone veark.209WPW'li hastanın asemptomatik olan 129'unu (\%62) ortalama 38 ay takip ettikleri çalışmada; 33'ünde(\% 16) aritmik olay yaşadıklarını gözlemlemiş, bu 33 hastanın 25'inde SVT, 8'inde atriyal fibrilasyon (AF), 3'ünde ventriküler fibrilasyon (VF) (iki hastada AF sonrası VF'ye dönüşme, birinde ise ölüm) geliştiği belgelenmiştir[17]. 2014 yılında Pappone ve ark. asemptomatik olan ve ablasyon uygulanmayan 550 hastanın ortalama 22 aylık takiplerinde, hastaların tamamını çocuk ve adelosanlardan oluşan 13'ünde (\% 2) VF geliştiğini belirtmiştir [18]." 2015 Amerikan Kardiyoloji Koleji (ACC) / Amerikan Kalp Cemiyeti (AHA) / Kalp Ritm Derneği (HRS) Supraventriküler Taşikardili Yetişkin Hasta Yönetimi Klavuzunda"; Elektrofizyolojik çalışma'nın (EFÇ), preeksitasyonu olan asemptomatik hastalarda, aritmik olaylar için risk sınıflandırması yapmak için uygun bir yöntem olduğu vurgulanmıştır[15]. Semptomların yokluğunda, klinik öncelik, artmış aritmik olay riski taşıyan aksesuar yolakları belirlemek için yapılan EFÇ'de; a) İndüklenmiş AF sırasında en kısa R-R aralığının < 250 msn olması b) Birden fazla aksesuar yol varlığı c) Sürekli AVRT'nin indüklenmesi d) Aksesuar yolun refrakter periodunun $<240$ msn olması maddelerinin bir yada daha fazlasının olması malign aritmi gelişimi ile korelasyon gösterdiği saptanmıştır[17-19]. Vaka serimize dahil olan asemptomatik preeksitasyonlu hastalara, tüm bu verilere ve kılavuz bilgilerine dayanarak ablasyon tedavisi uygulandı. Ancak EFÇ'de malign aritmi açısından yüksek risk kriterleri saptanmayan hastalara, ablasyon tedavisinin olası riskleri dikkate alınarak, olası kar-zarar hesabı yapılıp tedavi planlaması yapılabilinir.

\section{Sonuç}

SVT grubun ikinci sıklıkta görülen üyesi olan AVRT'nin bilinen küratif tedavisi radyofrekans katater ablasyondur. 232 hastayı kapsayan tek merkez olgu serimizde, geçmiş kohort analizlerine kıyasla benzer akut ve uzun dönem başarı oranları görülmektedir. Komplikasyon sıklığı açısından bakıldığında aksesuar yol ablasyonu sonrası gelişen kalıcı AV blok oranları benzerlik göstermektedir. Ek olarak asemptomatik preeksitasyon saptanan hastalar, AKÖ açısından, elektrofizyolojik çalışma yapılarak değerlendirilmelidir.

\section{Maddi Destek ve Çıkar illişkisi}

Çalışmayı maddi olarak destekleyen kişi/kuruluş yoktur ve yazarların çıkara dayalı bir ilişkisi yoktur.

\section{Kaynaklar}

1. Katritsis D.G, G Boriani, FG Cosio et al. European Heart Rhythm Association (EHRA) consensus document on the management of supraventricular arrhythmias, endorsed by Heart Rhythm Society (HRS), Asia-Pacific Heart Rhythm Society (APHRS), and Sociedad Latinoamericana de Estimulación Cardiaca y Electrofisiologia (SOLAECE). EP Europace 2017; 19: 465-511 
2. Porter, M.J, JB Morton, R Denman et al. Influence of age and gender on the mechanism of supraventricular tachycardia. Heart Rhythm 2004; 1: 393-96.

3. Issa Z, M.J , Zipes DP, Issa Z et al. Atrioventricular reentrant tachycardia. In: Issa ZF,Miller JM, Zipes DP (eds). Clinical Arrhythmology and Electrophysiology: A Companion to Braunwald's Heart Disease.ElsevierW.B. Saunders, Philadelphia; 2012: p411-67.

4. Pappone C, G Vicedomini, F Manguso et al. WPW syndrome in the era of catheter ablation: insights from a registry study of 2169 patients. Circulation 2014; 130: 811-19

5. Jackman, W.M, X Wang, KJ Friday et al. Catheter ablation of accessory atrioventricular pathways (Wolff-Parkinson-White syndrome) by radiofrequency current. New England Journal of Medicine 1991; 32: 1605-11.

6. Page, R.L, JA Joglar, MA Caldwell et al., 2015 ACC/AHA/ HRS guideline for the management of adult patients with supraventricular tachycardia: a report of the American College of Cardiology/American Heart Association Task Force on Clinical Practice Guidelines and the Heart Rhythm Society. J Am Coll Cardiol 2016; 67: 27-115

7. Ranjan KT, George JK, Raymond Y. Radiofrequency catheter ablation in patients with Wolff-Parkinson-White syndrome. Can Med Assoc J 1994; 151: 771-76

8. Gaita F, Riccardi R, Hocini M et al. Safety and efficacy of cryoablation of accessory pathways adjacent to the normal conduction system. J Cardiovasc Electrophysiol 2003; 14: 825-29

9. Arruda MS, McClelland JH, Wang $X$ et al. Development and validation of an ECG algorithm for identifying accessory pathway ablation site in Wolff-Parkinson-White syndrome. J Cardiovasc Electrophysiol 1998; 9: 2-12.

10. Calkins $\mathrm{H}$, Yong P, Miller JM et al. Catheter ablation of accessory pathways, atrioventricular nodal reentrant tachycardia, and the atrioventricular junction: final results of a prospective, multicenter clinical trial. The Atakr Multicenter Investigators Group. Circulation 1999; 99: 262-70.
11. Spector $\mathrm{P}$, Reynolds $\mathrm{MR}$, Calkins $\mathrm{H}$ et al. Metaanalysis of ablation of atrial flutter and supraventricular tachycardia. Am J Cardiol 2009; 104: 671-77.

12. Packer DL. Three-dimensional mapping in interventional electrophysiology: techniques and technology. Journal of Cardiovascular Electrophysiology 2005; 16: 1110-16.

13. Bhakta $D, \&$ Miller, J. M. Principles of electroanatomic mapping. Indian Pacing and Electrophysiology Journal 2008; 8: 32-50

14. J Romero, F Lupercio, D Goodman-Meza et al. "Electroanatomic mapping systems (CARTO/EnSite NavX) vs. conventional mapping for ablation procedures in a training program", J Interv Card Electrophysiol 2016; 45: 71-80

15. Al-Khatib SM, Arshad A, Balk EM et al. Risk stratification for arrhythmic events in patients with asymptomatic pre-excitation: a systematic review for the 2015 ACC/AHA/HRS guideline for the management of adult patients with supraventricular tachycardia: a report of the American College of Cardiology/ American Heart Association Task Force on Clinical Practice Guidelines and the Heart Rhythm Society. J Am Coll Cardiol 2016; 67: 1617-29.

16. Al-Khatib SM, Pritchett EL. Clinical features of Wolff-ParkinsonWhite syndrome. Am Heart J 1999; 138: 403-13.

17. Pappone C, Santinelli V, Rosanio S et al. Usefulness of invasive electrophysiologic testing to stratify the risk of arrhythmic events in asymptomatic patients with Wolff-Parkinson-White pattern: results from a large prospective long-term follow-up study. J Am Coll Cardiol 2003; 41: 239-44.

18. Pappone C, Vicedomini G, Manguso F et al. Wolff-Parkinsonwhite syndrome in the era of catheter ablation: insights from a registry study of 2169 patients. Circulation 2014; 130: 811-19.

19. Brembilla-Perrot B, Holban I, Houriez P et al. Influence of age on the potential risk of sudden death in asymptomatic Wolff-ParkinsonWhite syndrome. Pacing Clin Electrophysiol 2001; 24: 1514-18. 